\title{
An exploration study to find important factors influencing on expert systems
}

\author{
Naser Azad*, Mohammad Teymouri, Reyhaneh Malekzadeh and Seyed Foad Zarifi
}

Department of Management, Islamic Azad University, South Tehran Branch, Tehran, Iran

\begin{tabular}{l}
\hline C H R O N I C L E \\
\hline Article history: \\
Received May 16, 2013 \\
Received in revised format \\
28 June 2013 \\
Accepted 10 August 2013 \\
Available online \\
August 112013 \\
\hline Keywords: \\
Expert systems \\
Factor analysis \\
Knowledge management \\
Intelligence system \\
Neural network
\end{tabular}

\begin{abstract}
A B S T R A C T
Knowledge management plays an important role in modern management systems since many existing systems move towards learning organizations. Expert systems, on the other hand, are considered as the most popular techniques for adapting recent developments on knowledge management. This paper presents an empirical investigation to find important factors influencing adaptation of expert systems. The proposed study designs a questionnaire in Likert scale consists of 25 questions, distributes it among 258 people who have recently graduated from computer science and they are familiar with implementation of expert systems. Cronbach alpha is calculated as 0.730 and Kaiser-Meyer-Olkin Measure of Sampling Adequacy and Approx. Chi-Square are 0.748 and 1377.397, respectively. The study has implemented principal component analysis and the results have indicated that there were four factors influencing expert systems including systems management, intelligence systems, system analysis and specialized analysis.
\end{abstract}

\section{Introduction}

Knowledge management plays essential role in modern management systems and management of many organizations are presently planning to move towards learning organizations. Expert systems, on the other hand, are considered as the most popular techniques for adapting recent developments on knowledge management. During the past few decades, there have been tremendous efforts on building value added expert systems (Shiau, 2011). Jayaraman and Srivastava (1996), for instance, defined an expert system (ES) as a decision-making tool, which captures perishable expertise from an expert and stores this knowledge in the computer, and also as a computer system, which could solve problems using human expertise and knowledge of the system environment. Ranjan and Tripathi (2008) measured competencies of some organizations using expert system for a case of institutional perspective. Lee and Lee (2011) presented an application of factor analysis for classifying and illuminating the nature of distinct dimensions of service research and development (R\&D). 
The application was based on the concept that firms could benefit from clarifying R\&D and R\&D-like activities to help their $R \& D$ decision. They used principal component analysis (PCA) of factor analysis to transfer a number of possibly correlated R\&D activities into a smaller number of uncorrelated activities called principal components, and business unit could detect the patterns of service R\&D, express their similarities and differences, and develop its R\&D portfolio. Papić et al. (2009) presented a fuzzy expert system for scouting and evaluation of young sport talents. They also made a comparison between the sport proposed by their expert system and the actual outcome of the person's sports career and reported high reliability and accuracy of the developed system.

Hsu (2012) performed an investigation to detect the key factors influencing blog design, and explored the causal relationships between the criteria for each factor. The study adopted a model which is a hybrid of factor analysis and the Decision Making Trial and Evaluation Laboratory method (DEMATEL). The DEMATEL method was implemented to simplify and to visualize the interrelationships between criteria in making a decision. They found five core factors, which influence blog design including visual clarity, interface and usability, content and searchability, programming, and sociability. Besides, the key criteria for each factor were detected and the impact- relation maps were detected. The results of this study can provided useful guidance to blog designers for developing better blog platforms.

Yang (2011) presented a classification-based Kansei engineering system for modeling consumers' affective responses and analyzing product form features. Tung and Lee (2010) presented an innovative performance evaluation model of grey factor analysis for a case study of listed biotechnology corporations in Taiwan. Hsia et al. (2009) presented a factor analysis based selection process for predicting successful university color guard club members. Kositanurit et al. (2011) re- examined information systems (IS) user performance based on some data mining to identify properties of IS that lead to highest levels of user performance. Martínez-Torres et al. (2012) explored website link structure by considering websites as interconnected graphs and analyzing their features as a social network.

This paper presents an implementation of factor analysis to find important factors influencing expert systems. The implementation of factor analysis has recently become popular among researchers. Azad et al. (2013a), for instance, performed an exploration study to find important factors influencing product positioning in Iranian food industry. Azad et al. (2013b) performed another investigation to determine influential factors on implementation of management information system (MIS). They used factor analysis to find important factors and detected six important factors including fear of technology, organizational instability, informal groups, cultural factors, organizational development and understanding that change is always good.

\section{The proposed study}

This paper presents an empirical investigation to find important factors influencing implementation of expert systems in organizations. The study is performed among recently graduated engineers from the field of computer science in one of schools located in city of Qom, Iran. The study selected the questionnaire among all population and no sampling was performed. The proposed study designs a questionnaire in Likert scale consists of 25 questions, distributes it among all 258 people who have recently graduated from computer science and they have good background on expert systems. Cronbach alpha is calculated as 0.730. In addition, Kaiser-Meyer-Olkin Measure of Sampling Adequacy and Approx. Chi-Square are 0.748 and 1377.397, respectively. Since we plan to factor analysis and this method is sensitive to skewness of the data we decided to remove 9 questions whose skewness values were not within acceptable limits. The final Cronbach alpha was calculated as 0.74 , which was reasonably acceptable. 


\section{Scree Plot}

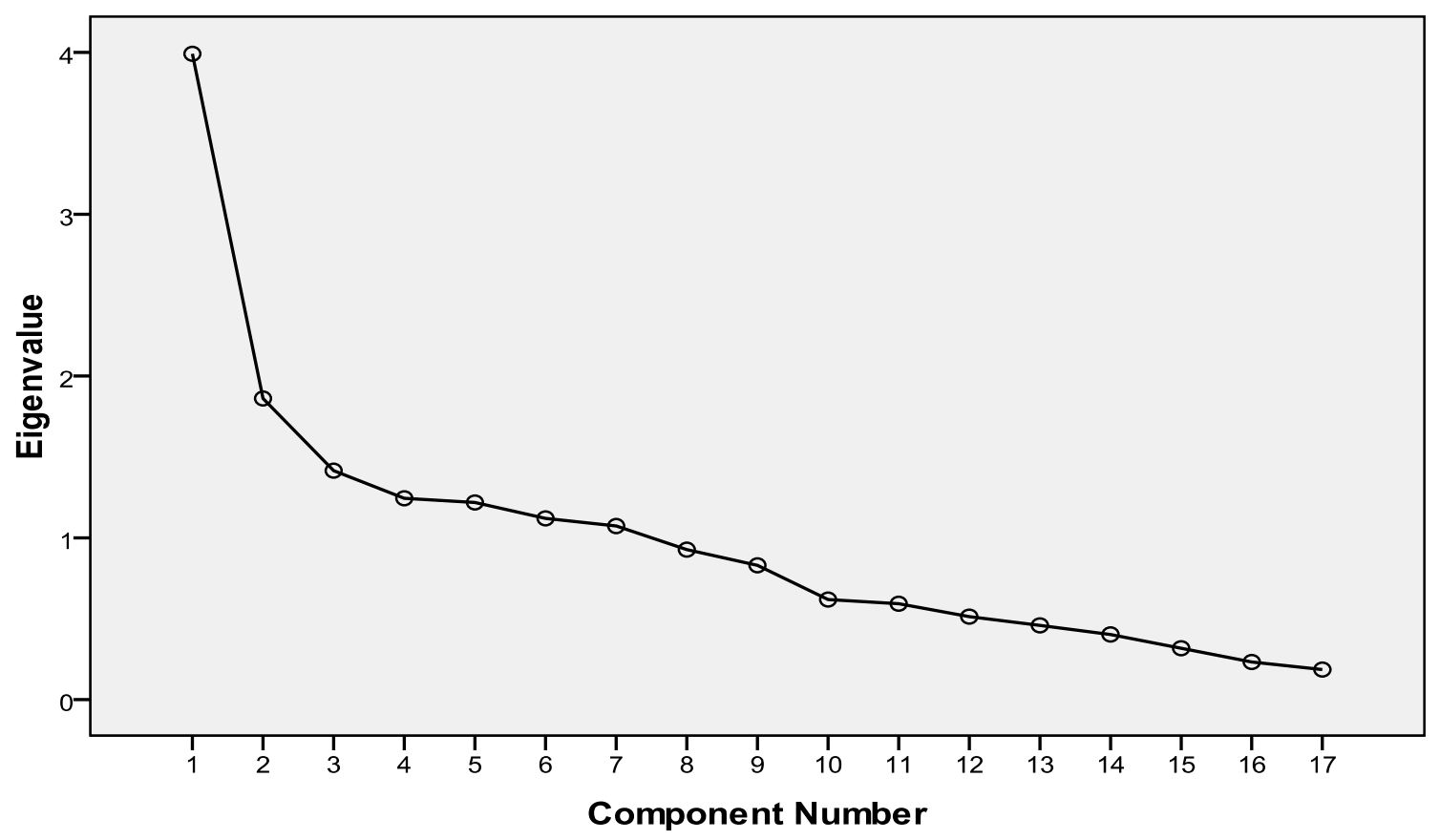

Fig. 1. Scree plot of the proposed study

Table 1 demonstrates the results of communalities on various factors.

Table 1

The results of communalities based Principal Component Analysis

\begin{tabular}{llc}
\hline Description & Initial & Extraction \\
\hline 1.Data center & 1.000 & .759 \\
2.Hybrid of multi databases & 1.000 & .713 \\
3. Artificial intelligence & 1.000 & .702 \\
4.Simulation of performance & 1.000 & .595 \\
5.Neural network & 1.000 & .691 \\
6.Communication processes & 1.000 & .723 \\
7.Decision support systems & 1.000 & .573 \\
8.Knowledge engineering & 1.000 & .752 \\
9.Capacity planning & 1.000 & .746 \\
10.Specialty & 1.000 & .597 \\
11.Environment changes & 1.000 & .569 \\
12.Innovation in data processing & 1.000 & .727 \\
13.Modeling & 1.000 & .826 \\
14.Knowledge experiments & 1.000 & .720 \\
15.Knowledge assessment & 1.000 & .694 \\
16.Recognizing objectives & 1.000 & .792 \\
17.Management information system & 1.000 & .744 \\
\hline
\end{tabular}

Table 2 demonstrates the results of principal component analysis. 


\section{Table 2}

The summary of principal component analysis

\begin{tabular}{|c|c|c|c|c|c|c|c|c|c|}
\hline \multirow[t]{2}{*}{ Component } & \multicolumn{3}{|c|}{ Initial Eigenvalues } & \multicolumn{3}{|c|}{ Extraction Sums of Squared Loadings } & \multicolumn{3}{|c|}{ Rotation Sums of Squared Loadings } \\
\hline & Total & $\%$ of Variance & Cumulative \% & Total & $\%$ of Variance & Cumulative \% & Total & $\%$ of Variance & Cumulative \% \\
\hline 1 & 3.992 & 23.481 & 23.481 & 3.992 & 23.481 & 23.481 & 3.764 & 22.140 & 22.140 \\
\hline 2 & 1.861 & 10.949 & 34.430 & 1.861 & 10.949 & 34.430 & 1.532 & 9.011 & 31.152 \\
\hline 3 & 1.415 & 8.323 & 42.753 & 1.415 & 8.323 & 42.753 & 1.492 & 8.774 & 39.926 \\
\hline 4 & 1.244 & 7.319 & 50.072 & 1.244 & 7.319 & 50.072 & 1.361 & 8.008 & 47.934 \\
\hline 5 & 1.219 & 7.168 & 57.240 & 1.219 & 7.168 & 57.240 & 1.285 & 7.560 & 55.494 \\
\hline 6 & 1.120 & 6.590 & 63.830 & 1.120 & 6.590 & 63.830 & 1.257 & 7.394 & 62.888 \\
\hline 7 & 1.073 & 6.310 & 70.140 & 1.073 & 6.310 & 70.140 & 1.233 & 7.252 & 70.140 \\
\hline 8 & .927 & 5.451 & 75.591 & & & & & & \\
\hline 9 & .830 & 4.880 & 80.471 & & & & & & \\
\hline 10 & .618 & 3.637 & 84.108 & & & & & & \\
\hline 11 & .592 & 3.483 & 87.591 & & & & & & \\
\hline 12 & .513 & 3.017 & 90.608 & & & & & & \\
\hline 13 & .459 & 2.699 & 93.307 & & & & & & \\
\hline 14 & .402 & 2.367 & 95.675 & & & & & & \\
\hline 15 & .317 & 1.867 & 97.542 & & & & & & \\
\hline 16 & .232 & 1.367 & 98.909 & & & & & & \\
\hline 17 & .186 & 1.091 & 100.000 & & & & & & \\
\hline
\end{tabular}

As we can observe from the results of Fig. 1, there are four factors whose Eigenvalues are greater than one and, therefore, extract five factors, which are next in the results section.

\section{The results}

In this section, we present details of our findings on four important criteria influencing our investigation.

\section{Table 3}

The summary of factor analysis

\begin{tabular}{|c|c|c|c|c|c|}
\hline Factor & Measurable variable & Weight & Eigenvalue & Variance & Accumulated \\
\hline \multirow{5}{*}{$\begin{array}{l}\text { Systems } \\
\text { management }\end{array}$} & Modeling & 0.859 & 3.992 & 23.481 & 23.481 \\
\hline & Description of objectives & 0.857 & & & \\
\hline & Management information systems & 0.840 & & & \\
\hline & Knowledge evaluation & 0.821 & & & \\
\hline & Knowledge experiment & 0.765 & & & \\
\hline \multirow{5}{*}{$\begin{array}{l}\text { Intelligence } \\
\text { System }\end{array}$} & Neural network & 0.738 & 1.861 & 34.430 & 34.430 \\
\hline & Artificial intelligence & 0.703 & & & \\
\hline & Access to more than one database & 0.440 & & & \\
\hline & Communication process & 0.403 & & & \\
\hline & Decision support systems & 0.359 & & & \\
\hline \multirow{3}{*}{ System analysis } & Innovation in process & 0.812 & 1.415 & 42.753 & 42.753 \\
\hline & Knowledge database & 0.534 & & & \\
\hline & Environment change & 0.459 & & & \\
\hline \multirow{3}{*}{$\begin{array}{l}\text { Specialized } \\
\text { analysis }\end{array}$} & Simulation of performance & 0.634 & 1.244 & 50.072 & 50.072 \\
\hline & Specialty & 0.592 & & & \\
\hline & Knowledge engineering & 0.523 & & & \\
\hline
\end{tabular}

As we can observe from the results of Table 3, there are four factors associated with the proposed study including systems management, intelligence system, system analysis and specialized analysis.

\section{Discussion and conclusion}

In this survey, we have performed an investigation on measuring the impact of various factors on implementation of expert systems in Iran. The study has implemented principal component analysis and the results have indicated that there were four factors influencing 
implementation of expert systems including, systems management, intelligence system, system analysis and specialized analysis.

In terms of systems management, there are five sub-components where modeling is the most important factor followed by description of objectives, management information systems, knowledge evaluation and knowledge experiment. The second factor, intelligence system, consists of five factors including neural network, artificial intelligence, accessing to more than one database, communication process and decision support systems. In this group, neural network is the most influential factor followed by artificial intelligence. The third factor, systems design, consists of three factors, which are organizational consistency, inter-cultural coordination and enterprise resource planning. Finally, the last item is specialized analysis and this item includes three options including simulation of performance, specialty and knowledge engineering. In this group, simulation performance is considered the most influential one followed by specialty and knowledge engineering.

\section{Acknowledgment}

The authors would like to thank the anonymous referees for their construction comments on earlier version of this work.

\section{References}

Azad, N., Abbasi, N., \& Zarifi, S.F. (2013a). A study to determine influential factors on product positioning. Management Science Letters, 3(8), 2229-2234.

Azad, N., Zamani, T., \& Zarifi, S.F. (2013b). A study to determine influential factors on implementation of management information system. Management Science Letters, 3(8), 2235-2240.

Hsia, T.C., Hsu, Y.L., \& Jen, H.L. (2009). A factor analysis based selection process for predicting successful university color guard club members. Expert Systems with Applications, 36(2), 2719-2726.

Hsu, C.C. (2012). Evaluation criteria for blog design and analysis of causal relationships using factor analysis and DEMATEL. Expert Systems with Applications, 39(1), 187-193.

Jayaraman, V., \& Srivastava, R. (1996). Expert systems in production and operations management: current applications and future prospects. International Journal of Operations \& Production Management, 16(12), 27-44.

Kositanurit, B., Osei-Bryson, K.M., \& Ngwenyama, O. (2011). Re-examining information systems user performance: Using data mining to identify properties of IS that lead to highest levels of user performance. Expert Systems with Applications, 38(6), 7041-7050.

Lee, Y., \& Lee, H. (2011). Application of factor analysis for service R\&D classification: A case study on the Korean ICT industry. Expert Systems with Applications, 38(3), 2119-2124.

Martínez-Torres, M.R., Toral, S.L., Palacios, B., Barrero, F. (2012). An evolutionary factor analysis computation for mining website structures. Expert Systems with Applications, 39(14), 11623-11633.

Papić, V., Rogulj, N., \& Pleština, V. (2009). Identification of sport talents using a web-oriented expert system with a fuzzy module. Expert Systems with Applications, 36(5), 8830-8838.

Ranjan, J., \& Tripathi, P. (2008). Measuring competencies using expert system: Institutional perspective. Journal of Theoretical and Applied Information Technology, 95-104.

Shiau, W. L. (2011). A profile of information systems research published in expert systems with applications from 1995 to 2008. Expert Systems with Applications, 38(4), 3999-4005.

Tung, C.T., \& Lee, Y.J. (2010). The innovative performance evaluation model of grey 
factor analysis: A case study of listed biotechnology corporations in Taiwan. Expert Systems with Applications, 37(12), 7844-7851.

Yang, C.C. (2011). A classification-based Kansei engineering system for modeling consumers' affective responses and analyzing product form features. Expert Systems with Applications, 38(9), 11382-11393. 